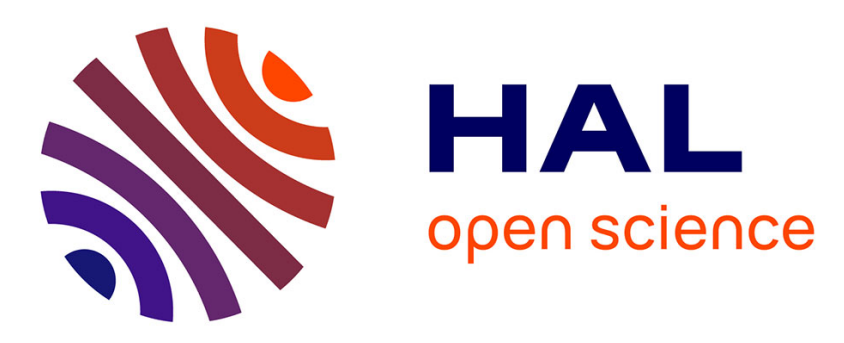

\title{
Bronchiolitis Admissions to Intensive Care During COVID
}

Jérôme Rambaud, Stéphane Dauger, Luc Morin, Jean Bergounioux, Pierre-Louis Leger, Ricardo Carbajal, Sylvain Renolleau, Romain Guedj

\section{To cite this version:}

Jérôme Rambaud, Stéphane Dauger, Luc Morin, Jean Bergounioux, Pierre-Louis Leger, et al.. Bronchiolitis Admissions to Intensive Care During COVID. Pediatrics, 2021, pp.e2021050103. 10.1542/peds.2021-050103 . hal-03174889

\section{HAL Id: hal-03174889 \\ https://hal.sorbonne-universite.fr/hal-03174889}

Submitted on 19 Mar 2021

HAL is a multi-disciplinary open access archive for the deposit and dissemination of scientific research documents, whether they are published or not. The documents may come from teaching and research institutions in France or abroad, or from public or private research centers.
L'archive ouverte pluridisciplinaire HAL, est destinée au dépôt et à la diffusion de documents scientifiques de niveau recherche, publiés ou non, émanant des établissements d'enseignement et de recherche français ou étrangers, des laboratoires publics ou privés. 


\title{
Bronchiolitis Admissions to Intensive Care during COVID
}

Jérôme Rambaud ${ }^{1}$ MD PhD, Stéphane Dauger ${ }^{2}$ MD PhD, Luc Morin ${ }^{3,4}$ MD MSc, Jean Bergounioux ${ }^{5}$, MD PhD, Pierre-Louis Leger ${ }^{1}$ MD PhD, Ricardo Carbajal ${ }^{6,7}$ MD PhD, Sylvain Renolleau ${ }^{8}$ MD PhD, Romain Guedj ${ }^{6,7}$ MD PhD

\author{
Affiliations \\ ${ }^{1}$ Pediatric Intensive Care Unit, APHP Hôpital Armand Trousseau - Sorbonne Université, \\ faculté de médecine, Paris, France. \\ 2 Pediatric Intensive Care Unit, APHP, Hôpital Robert Debré - Université de Paris. Paris, \\ France \\ ${ }^{3}$ Université Paris-Saclay, AP-HP, Service de réanimation pédiatrique et néonatale, Hôpital \\ Bicêtre, DMU 3 Santé de l'enfant et de l'adolescent, Le Kremlin-Bicêtre, France \\ ${ }^{4}$ Institute of Integrative Biology of the Cell, CNRS, CEA, Paris Saclay University, Gif-Sur- \\ Yvette, France \\ ${ }^{5}$ Pediatric Neurology and Intensive Care Unit, APHP Hôpital Raymond-Poincaré. Garches, \\ France \\ ${ }^{6}$ Pediatric Emergency Deparment, APHP Hôpital Armand Trousseau-Sorbonne Université, \\ faculté de médecine, Paris, France \\ ${ }^{7}$ INSERM UMR1153, Paris, France \\ ${ }^{8}$ Pediatric Intensive Care Unit, APHP Hôpital Necker Enfants Malades - Université de Paris. \\ Paris, France
}

Address correspondence to: Ricardo Carbajal, MD, PhD. Pediatric Emergency Department, APHP Hôpital Armand Trousseau. 26, av du Dr Netter 75012 Paris, France.

Email: ricardo.carbajal@aphp.fr

Phone +33144736487

Short title: Bronchiolitis Admissions during COVID 
CONFLICTS OF INTEREST: The authors have no conflicts of interest to declare FUNDING: No external funding.

Ethics: Due to its retrospective nature, on deidentified data, and based on diagnostic codes, informed consent is waived within the provisions of the French Public Health Code

\section{ABBREVIATIONS:}

- COVID-19: coronavirus

- PICU: pediatric intensive care unit

\section{Contributors' Statement page}

Romain Guedj, Jerome Rambaud, and Ricardo Carbajal conceived and designed the study, performed the statistical analyses, wrote the first draft of the manuscript, and reviewed and revised the manuscript.

Stéphane Dauger, Luc Morin, Jean Bergounioux, Pierre-Louis Leger, and Sylvain Renolleau, collected the data and critically reviewed the manuscript for important intellectual content.

All authors approved the final manuscript as submitted and agree to be accountable for all aspects of the work. 


\section{INTRODUCTION}

Acute bronchiolitis, a viral seasonal infection of the lower respiratory tract, affects nearly $20 \%$ of all children and leads to the hospitalization of $2 \%$ to $3 \%$ of all children younger than 12 months every year ${ }^{1,2}$. Approximately 2 to $6 \%$ of hospitalized children require admission to the pediatric intensive care unit (PICU) ${ }^{1}$. Acute bronchiolitis may account for as much as $13 \%$ of PICU admissions ${ }^{3}$ and it is responsible for the death of around 3/100 000 children under 12 months each year ${ }^{4} ;$ e.g., nearly 20 and 100 infants annually in England ${ }^{4}$ and the United States $^{5}$, respectively. Bronchiolitis epidemic has a predictable seasonal pattern, and in France, it starts in September, peaks in November-December, and ends in February. Although children have been relatively spared by the COVID-19 pandemic, the impact that the overlap of the second wave of this pandemic and of the associated public measures have on the 20202021 bronchiolitis season in the Northern hemisphere is unknown.

The aim of this multicenter regional study is to determine the effect of the COVID-19 second wave in France and the public measures it elicited, i.e., social distancing, mask-wearing, hand hygiene, curfews, and lockdowns, on the number of admissions for bronchiolitis to all PICUs of the largest region of France, and its related deaths.

\section{METHODS}

From the electronic health record systems, we identified all children (age <2 years) admitted to all 5 PICUs of the region of Paris (12.6 million inhabitants representing around $20 \%$ of France population) for bronchiolitis from September 2015 through December 2020. Bronchiolitis was defined using the ICD-10 codes. Based on the 5 bronchiolitis epidemics before COVID-19, (2015-2016 through 2019-2020), we calculated by Time Series Analysis (SPSS, v18; SPSS Inc, Chicago, USA) the predicted number of PICU admissions for the months of September through December 2020 (COVID season) and compared them to actual 
admissions. Informed consent was waived within the provisions of the French Public Health Code.

\section{RESULTS}

During the 5 pre-COVID-19 seasons there were 3099 admissions for bronchiolitis to all 5 PICUs; 2190/3099 (70.7\%) occurred between September and December. Figure 1 shows the monthly actual PICU admissions for each of the 5 pre-COVID-19 bronchiolitis seasons, a model fit created by time series analysis $\left(\mathrm{R}^{2}=0.93\right)$ and the predicted admissions for the first 4 months (September-December) of the COVID-19 bronchiolitis season. While the predicted number of admissions for bronchiolitis between September and December 2020 to all PICUs was 444 , the actual number of admissions was 65 ; i.e., an $85.3 \%$ reduction. Figure 2 shows the comparison of the predicted and actual admissions for September-December 2020. During the entire 5 pre-COVID-19 seasons there were 19 deaths for bronchiolitis and no death during the 4 first months of the COVID-19 season.

\section{DISCUSSION}

This regional study, including all PICUs of the Paris region, shows a dramatic reduction in the number of admissions of young infants to PICUs for bronchiolitis during the COVID era. Because of the exhaustive recruitment in a region representing around $20 \%$ of France population, these results could be extrapolated to the whole country since the same public measures were taken. During the first 4 months of the current bronchiolitis season, there were nearly 370 fewer PICU admissions for bronchiolitis in infants than expected in the Region of Paris. This represents an important reduction of the severe bronchiolitis burden on infants themselves, infants' families, and the management of PICU beds. Although we are unable to quantify it, it is also possible that the deaths of some infants due to bronchiolitis were avoided. Our findings, in a country of the Northern hemisphere, are consistent with a marked 
decrease in detections of Respiratory Syncytial Virus (RSV), the main causative virus of bronchiolitis, reported during the 2020 winter in the Southern hemisphere ${ }^{6}$.

The observed results could most probably be the consequence of the measures imposed to curb the COVID-19 pandemic such as social distancing, curfews, lockdowns, as well as hygiene measure, which may have had a major impact on the spreading of bronchiolitis viruses, especially the RSV. This draws attention to the role of adults in bronchiolitis virus spreading and suggests that in the future some of the hygiene measures used could be adapted to decrease the bronchiolitis burden in infants. Interestingly, this reduction was observed while schools and nurseries remained open. Nonetheless, it is also plausible that school attendance may have decreased or that infection control measures instituted in schools and nurseries may have prevented viral transmission. Finally, the decrease in PICU admissions for bronchiolitis cannot be explained by a reduction in available pediatric beds during COVID-19 because children have been spared by the pandemic and also because a marked reduction of total visits to pediatric emergencies departments was observed during COVID-197 ${ }^{7}$ Although the studied period does not encompass the whole bronchiolitis epidemic, this period usually accounts for more than $70 \%$ of the entire bronchiolitis season admissions.

\section{REFERENCES}

1. Hasegawa K, Tsugawa Y, Brown DF, Mansbach JM, Camargo CA, Jr. Trends in bronchiolitis hospitalizations in the United States, 2000-2009. Pediatrics. 2013;132(1):28-36.

2. Meissner HC. Viral Bronchiolitis in Children. N Engl J Med. 2016;374(1):62-72.

3. Green CA, Yeates D, Goldacre A, Sande C, Parslow RC, McShane P, et al. Admission to hospital for bronchiolitis in England: trends over five decades, geographical variation and association with perinatal characteristics and subsequent asthma. Arch Dis Child. 2016;101(2):140-146.

4. Fleming DM, Pannell RS, Cross KW. Mortality in children from influenza and respiratory syncytial virus. J Epidemiol Community Health. 2005;59(7):586-590.

5. Byington $\mathrm{CL}$, Wilkes J, Korgenski K, Sheng X. Respiratory syncytial virus-associated mortality in hospitalized infants and young children. Pediatrics. 2015;135(1):e24-31.

6. Yeoh DK, Foley DA, Minney-Smith CA, Martin AC, Mace AO, Sikazwe CT, et al. The impact of COVID-19 public health measures on detections of influenza and respiratory syncytial virus in children during the 2020 Australian winter. Clin Infect Dis. 2020. 
7. Angoulvant F, Ouldali N, Yang DD, Filser M, Gajdos V, Rybak A, et al. COVID-19 pandemic: Impact caused by school closure and national lockdown on pediatric visits and admissions for viral and non-viral infections, a time series analysis. Clin Infect Dis. 2020.

\section{Figure legends}

Figure 1. Monthly actual admissions of infants for bronchiolitis to all PICUs of the Region of Paris during the 5 pre-COVID-19 epidemics of bronchiolitis and predicted admissions for the season 2020-2021. PICU admissions during the 2020-2021 bronchiolitis season were predicted by time series analysis; the $\mathrm{R}^{2}$ of the model was 0.93 . The curves show the actual Pre-COVID-19 admissions, the fit of the admissions model and the predicted admissions for September through December 2020. The exact number of PICU admissions for bronchiolitis and the related deaths during the 5 pre-COVID-19 epidemic seasons are also shown.

PICU: Pediatric Intensive Care Unit. In France, each bronchiolitis epidemic season starts in September.

Figure 2. Actual and predicted admissions of infants for bronchiolitis to all PICUs of the Region of Paris (around 20\% of all France population) during the first 4 months of the 20202021 bronchiolitis epidemic. Dates of start of COVID-19 second wave in France, curfew and lockdown are shown. There was an $85.3 \%$ reduction between predicted and actual PICU admissions for bronchiolitis. *schools and nurseries for children remained open. PICU: Pediatric Intensive Care Unit. 


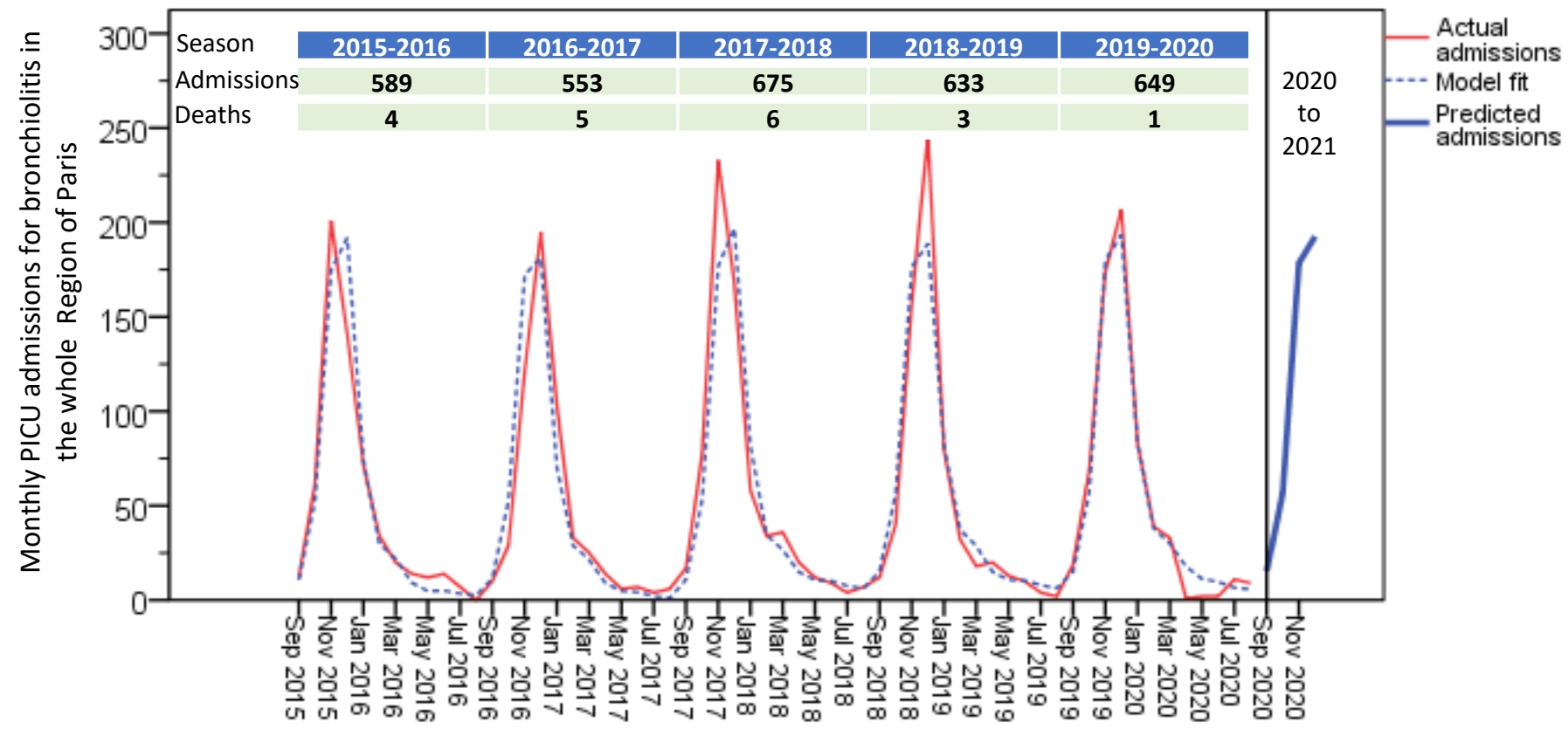

\section{Date}




\section{Actual and predicted PICU admissions for bronchiolitis during COVID-19 pandemic}

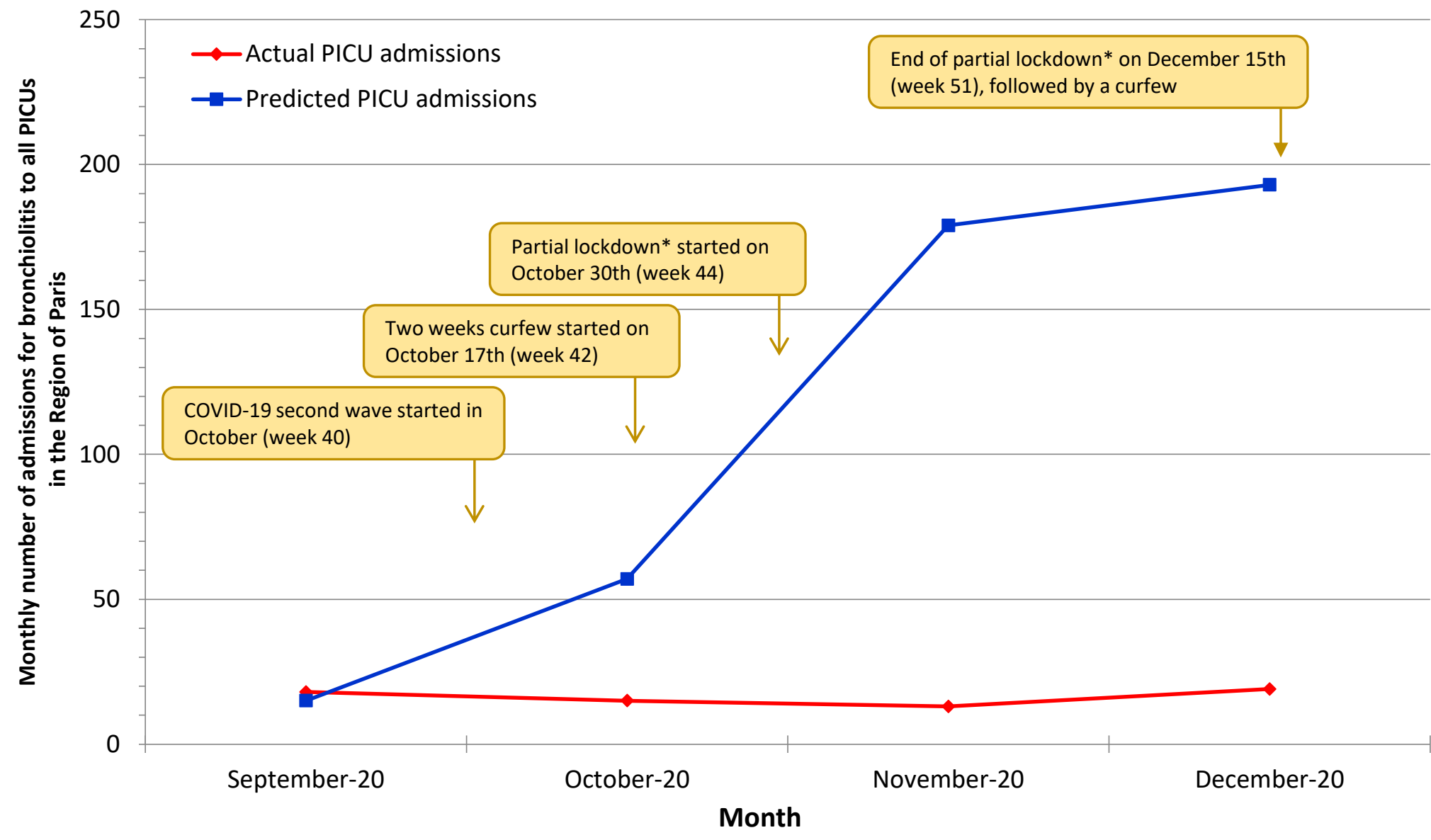

